The extensive health risks of asbestos have been clearly demonstrated in epidemiological and clinical research: There is little doubt that we can call ARDs a global epidemic of distressing proportions. An important, if hard won, legacy of this epidemic is the knowledge of the toxicology of fibrous materials that asbestos has taught us. This legacy has been well employed in regulation of man-made vitreous fibres (MMVF). Another expression of this legacy is that we currently spend about 250-300 million euros/year on nanotoxicology partially in order to prevent a ARDs like epidemic caused by an engineered nanomaterial. There is an irony in that, while we have been successful in eliminating asbestos like risks from other materials, asbestos itself is still around all over the world.

Some positive trends are however seen:

a. In policy:

- The number of countries banning asbestos grows (now 75)

- Intensive policy and practical interventions have been undertaken by the UN, the World Bank, the ILO, WHO, EU and the Council of Europe and several NGOs, not least the $\mathrm{ICOH}$

- Several countries have drawn up national asbestos profiles and launched national programmes for elimination of ARDs and national demolition programmes are proposed.

b. In practices:

- The global estimates of ARDs, derived from several sources, are converging

- Advances in clinical medicine allows for more accurate and earlier diagnosis of ARDs.

- New diagnostic entities are recognised as ARDs (e.g. larynx and ovarian cancers)

- Guidelines for good diagnostic practices and attribution are provided.

This Session will monitor all continents for the current asbestos situation and trends, consumption, health impact, policy and practical actions and proposals for future actions. We wish to produce proposals for further global actions by national and global actors.

\section{2b GLOBAL SITUATION IN THE ARDS}

K Straif . International Agency for Research on Cancer, Lyon, France

\subsection{6/oemed-2018-ICOHabstracts.631}

This presentation will serve as an introductory overview to the following presentations on regional trends and perspectives on asbestos related diseases (ARD). First, the evidence on
ARD will be summarized regarding asbestos related cancers (based on the IARC Monographs) and other asbestos related diseases (based on the Helsinki criteria). Next, a brief overview will discuss strengths and limitations of the different approaches to estimate the burden of ARD, and also point to ongoing activities on ARD. The presentation will conclude with global policy on the elimination of ARD.

\section{C ASBESTOS RELATED DISEASES IN ASIA: TRENDS AND PERSPECTIVES}

S-K Kang. Gachon University Gil Medical Centre, Republic of Korea

10.1136/oemed-2018-ICOHabstracts.632

Asbestos production and consumption Asbestos has not been widely used in Asia before 1970s. Asbestos consumption reached the peak in 1980s (Japan, Singapore) and 1990s (Korea). Since then, the consumption has sharply dropped in those countries. However, asbestos is continuously used in many Asian countries. The estimated amount of consumption in Asia is still approximately 2 million metric tons. More than Two-third of asbestos is being used in Asia while less than $20 \%$ had been consumed before 1970s. Most asbestos consumed in Asia was produced in China or imported from Canada and Russia.

Asbestos-related diseases Japan showed sharp increase of mesothelioma since 2005 and the number of mesothelioma has continuously increased in Korea since 2000. However, most Asian countries do not have data of asbestos-related diseases (ARD). The reasons would be the time lag between the exposure and outcomes and the lack of resources (accessibility, equipment, skilled manpower) needed for detecting ARDs.

Policies and practices Japan banned asbestos in 2006 after experiencing massive outbreak of ARDs, and followed by Korea (2009) and Brunei. Singapore technically banned asbestos although they did not announce the policy of ban on asbestos. Taiwan will ban asbestos by 2018. There are some countries to struggle against strong opposition to the direction of ban on asbestos. So far, Korea and Japan ratified the ILO Convention 162, which has been done by 35 countries in the world as of 2017.

Proposals for further actions Public awareness would be the most important factor to ban on asbestos in Asian countries. Social pressure would make the government do an action. Detecting cases of ARDs would be the effective way of persuading the policy makers based on Korean experience. A continuous pressure from international organisations or academic societies would be advantageous to those who are working on banning asbestos in the country. 